\title{
Structure of nanofibers derived from polycarbosilane using the polymer blend technique
}

Zormy Correa, Chiemi Ida and Asao Oya*

Polycarbosilane particles were dispersed in a novolac-phenolic resin matrix, and the resulting polymer blend was meltspun, stabilized and heat-treated at $1000^{\circ} \mathrm{C}$ or $1200{ }^{\circ} \mathrm{C}$ for $1 \mathrm{~h}$ in an inert atmosphere. The heat-treated blend fibers were oxidized in nitric acid solution to remove the carbon matrix and the nanofibers thus released were collected by filtration. The nanofibers obtained from the $1000^{\circ} \mathrm{C}$-blend fibers were oxidized more severely by nitric acid, resulting in a rougher nanofiber surface compared with that of nanofibers from the $1200^{\circ} \mathrm{C}$-blend fibers. The former nanofibers also showed a larger specific surface area $\left(288 \mathrm{~m}^{2} / \mathrm{g}\right)$ than did the latter $\left(44 \mathrm{~m}^{2} / \mathrm{g}\right)$. Analysis of a filament from the $1200{ }^{\circ} \mathrm{C}$-nanofibers showed carbon present at about 30 atom \%, whereas just a few atom $\%$ of carbon was found in the $1000{ }^{\circ} \mathrm{C}$-nanofiber. It was concluded that more intact nanofibers with stronger oxidation resistance were derived from the polymer blend fibers heated at a higher temperature.

\section{KEYWORDS : Silicon carbide, Nanofiber, Polymer blend, Spinning}

\section{Introduction}

Nanocomposites incorporating carbon nanotubes (CNTs) and carbon nanofibers (CNFs) as fillers have attracted considerable interest in recent years ${ }^{1}{ }^{1}$-3). However, such carbon materials cannot be used for composites consisting of metal or ceramic matrices because of their poor oxidation resistance. For these composites, silicon carbide can be successfully used instead ${ }^{4)}$. As for silicon carbide nanofibers, only whiskers are commercially available at present ${ }^{5)}$,6). These whiskers, however, have some practical problems associated with them : a small aspect ratio leading to low reinforcement ; high price reflecting difficulty of mass production ; and so on. This is the motivation behind the authors' development of a new method for preparing nanofibers from polycarbosilane (PCS) materials - a precursor of silicon carbide by using the polymer blend technique ${ }^{7)-9)}$.

In this method, PCS is initially dispersed in novolac-phenolic resin $(\mathrm{PF})$ and the resulting polymer blend is melt-spun. The blend fibers are stabilized, followed by heating to around $1000{ }^{\circ} \mathrm{C}$ in an inert atmosphere to carbonize the PF matrix and to transform PCS into an inorganic silicon carbide-based material. Finally, the fibers are oxidized in nitric acid to remove the carbon matrix, and the nanofibers thus released are recovered by filtration. The resulting nanofibers are several hundreds of $\mathrm{nm}$ in diameter and are long, possibly longer than $100 \mu \mathrm{m}$.

The authors' focus in this paper is oxidation of the nanofibers during the removal of matrix carbon by nitric acid. In particular, it was thought that nanofibers obtained from blend fibers heated at moderate temperatures were incompletely converted to inorganic material, and as a result, were subject to more severe oxidation. A commercial silicon carbide-based fiber, Nicalon, also shows inferior mechanical properties at high temperature with increasing oxygen content ${ }^{10)}$. In the present work, the nanofibers were obtained from PCS/PF blend fibers heated at $1000{ }^{\circ} \mathrm{C}$ or $1200{ }^{\circ} \mathrm{C}$, and their structures were examined by use of microscopic observations and other techniques.

\section{Experimental}

\subsection{Materials}

Polycarbosilane $\left(\left[-\mathrm{SiH}\left(\mathrm{CH}_{3}\right) \mathrm{CH}_{2-}\right]_{\mathrm{n}}\right.$, PCS type L, softening point $80^{\circ} \mathrm{C}$ ) was purchased from Nippon Carbon Co. Ltd. Novolacphenol formaldehyde resin $\left(\mathrm{PF}\right.$, softening point $100^{\circ} \mathrm{C}$ ) was kindly supplied by Gun-ei Chemical Co. Ltd.

\subsection{Preparation of nanofibers}

PCS and PF were completely dissolved in tetrahydrofuran, and the solvent was removed using a rotary evaporator to obtain a polymer blend, in which fine PCS particles were dispersed in a PF matrix. The blend was dried at $60^{\circ} \mathrm{C}$ under reduced pressure overnight and then continuously melt-spun at $100 \sim 110^{\circ} \mathrm{C}$ under an argon atmosphere 
using a conventional melt-spinning apparatus.

The polymer blend fibers were soaked for $16 \mathrm{~h}$ in an acid solution containing hydrochloric acid and formaldehyde as the main components, heated to $110{ }^{\circ} \mathrm{C}$ at $0.2{ }^{\circ} \mathrm{C} / \mathrm{min}$ and held for $16 \mathrm{~h}$ to cure the PF matrix. The cured fibers were heated at $1000{ }^{\circ} \mathrm{C}$ or $1200{ }^{\circ} \mathrm{C}$ under a nitrogen atmosphere. The heating rate and holding time were $100^{\circ} \mathrm{C} / \mathrm{h}$ and $1 \mathrm{~h}$, respectively. The resulting fibers were oxidized in $60 \%$ nitric acid at $180{ }^{\circ} \mathrm{C}$ for $10 \mathrm{~h}$ with gentle stirring and finally filtered using a $5 \mu \mathrm{m}$ membrane filter.

\subsection{Measurements}

The nanofibers were studied using a scanning electron microscope (SEM : JEOL JSM 5300), a field emission scanning electron microscope (FE-SEM : JEOL JSM 6700) and a transmission electron microscope (TEM : JEOL JEM-2010). An X-ray diffractometer (Rigaku RINT2000/PC) with CuK $\alpha$-radiation was used to examine the crystalline structure of the nanofibers. An automatic adsorption/ desorption apparatus (Nippon Bell, Belsorp 28SA) was used to analyze the porous structure of the nanofibers using nitrogen gas as the absorbent at $-196{ }^{\circ} \mathrm{C}(77 \mathrm{~K})$. The nanofibers were pre-treated at $200{ }^{\circ} \mathrm{C}$ for $2 \mathrm{~h}$ before the measurement. The elemental composition of a monofilament of the nanofiber was measured by an X-ray photoelectron spectrometer (XPS : Thermo Electron Theta Probe) using AlK $\alpha$ radiation by Sumika Chemical Analysis Service Co. A filament was etched with $\mathrm{Ar}^{+}$ions for up to $2500 \mathrm{sec}$, with the etch rate corresponding to $0.18 \mathrm{~nm} / \mathrm{sec}$ for $\mathrm{SiO}_{2}$ film.

\section{Results and discussion}

Fig.1 shows SEM photographs of the nanofibers obtained from blend fibers heated at $1000{ }^{\circ} \mathrm{C}$ and $1200{ }^{\circ} \mathrm{C}$, respectively referred to as $1000{ }^{\circ} \mathrm{C}$ - and $1200{ }^{\circ} \mathrm{C}$-nanofibers. The average diameter of the nanofibers was below $1 \mu \mathrm{m}$, although some scatter was seen in the diameters of both types of nanofibers. The $1000{ }^{\circ} \mathrm{C}$-nanofibers (Fig.1a)) were shorter than the $1200{ }^{\circ} \mathrm{C}$-nanofibers (Fig.1b)), because the former seemed to be fragile and were broken during the stirring in nitric acid. It should be noted that the nanofibers, particularly the $1200{ }^{\circ} \mathrm{C}$-nanofibers, were straight and very long.

Fig. 2 shows FE-SEM photographs of the $1000{ }^{\circ} \mathrm{C}$ - and $1200{ }^{\circ} \mathrm{C}$ nanofibers. There was some variability in the appearance of these nanofibers, but on the whole, the $1200{ }^{\circ} \mathrm{C}$-nanofiber showed a
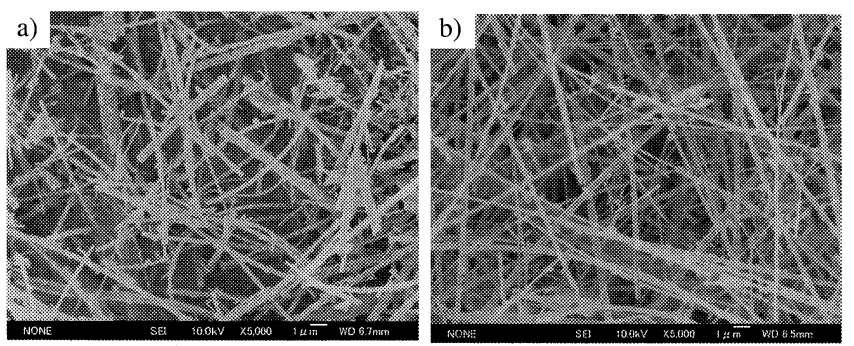

Fig.1 SEM photographs of nanofibers obtained from a) $1000{ }^{\circ} \mathrm{C}$ blend fibers and b) $1200^{\circ} \mathrm{C}$-blend fibers. smoother surface than $\operatorname{did}$ the $1000{ }^{\circ} \mathrm{C}$-nanofibers. Fig.2a) shows severe damage on a $1000{ }^{\circ} \mathrm{C}$-nanofiber. A very fine unevenness (pebblelike structure of ca. $10 \mathrm{~nm}$ ) was seen in both types of nanofiber.

Certain features of the nanofibers stood out at high magnification.

Figs. 3 and 4 show TEM photographs of the $1000{ }^{\circ} \mathrm{C}$ - and $1200{ }^{\circ} \mathrm{C}$ nanofibers. The structures depicted were generally seen in both types of nanofiber. As evident from Fig.3a) and b), the surface of the $1000^{\circ} \mathrm{C}$-nanofiber was very rough, possibly because of severe oxidation by nitric acid ${ }^{11)}$. Etched spots were occasionally observed, as illustrated in Fig.3c). Such etched spots were also observed in the $1200^{\circ} \mathrm{C}$ nanofibers (Fig.4a)), but the surface of the $1200^{\circ} \mathrm{C}$-nanofiber was far smoother (Fig.4b)), compared with that of the $1000{ }^{\circ} \mathrm{C}$-nanofiber.

As mentioned above, a major concern of the authors was whether a large amount of oxygen was being introduced into the nanofibers dur-
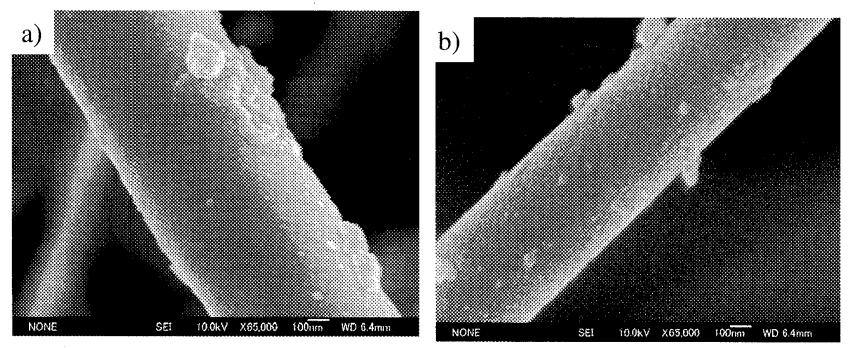

Fig.2 FE-SEM photographs of nanofibers obtained from a) $1000^{\circ} \mathrm{C}$ blend fibers and b) $1200{ }^{\circ} \mathrm{C}$-blend fibers.
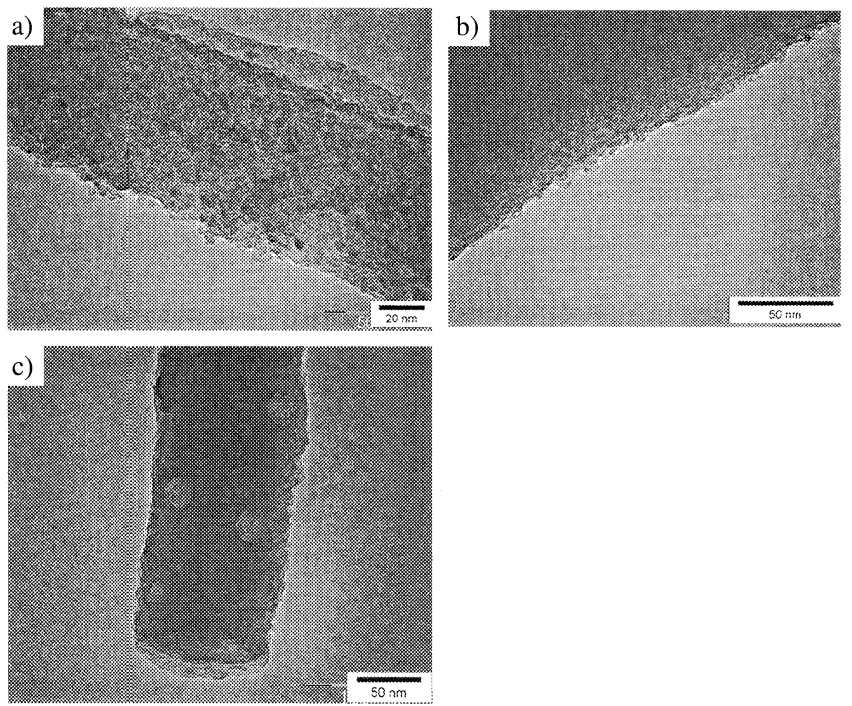

Fig.3 TEM photographs of nanofibers obtained from $1000{ }^{\circ} \mathrm{C}$-blend fibers.
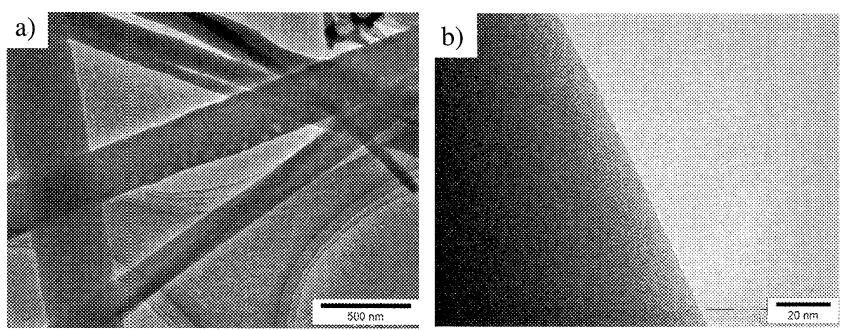

Fig.4 TEM photographs of nanofibers obtained from $1200{ }^{\circ} \mathrm{C}$-blend fibers. 


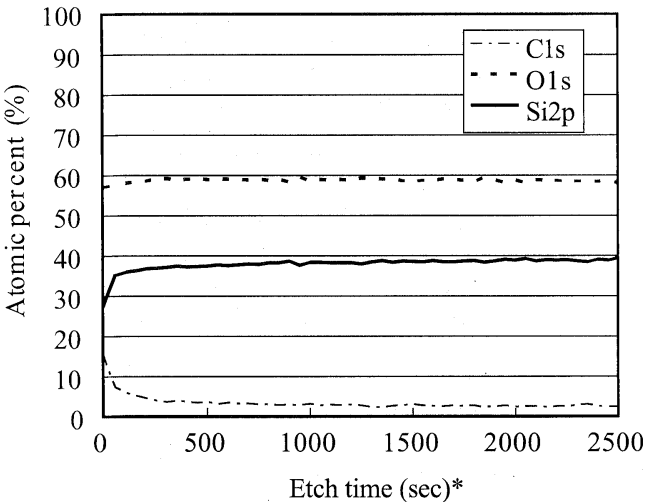

Fig.5 Changes in elemental composition of a monofilament obtained from $1000{ }^{\circ} \mathrm{C}$-nanofibers as a function of etch time. *The etch rate was $0.18 \mathrm{~nm} / \mathrm{sec}$ for $\mathrm{SiO}_{2}$ film.

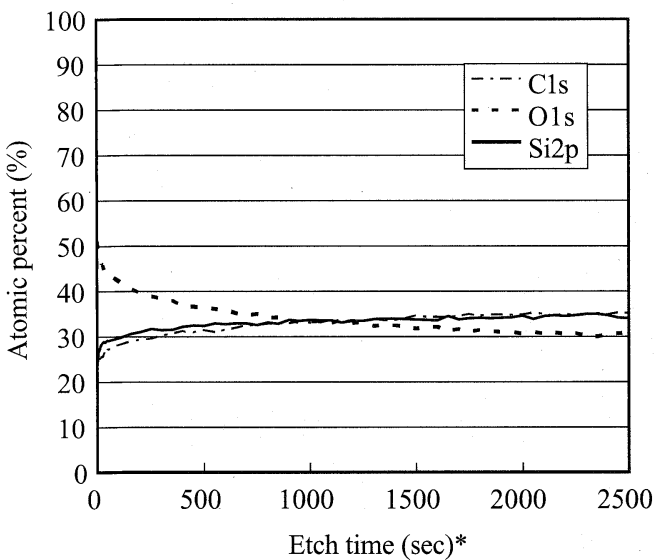

Fig.6 Changes in elemental composition of a nanofilament obtained from $1200^{\circ} \mathrm{C}$-nanofibers as a function of etch time. *The etch rate was $0.18 \mathrm{~nm} / \mathrm{sec}$ for $\mathrm{SiO}_{2}$ film.

ing the nitric acid oxidation process. Figs.5 and $\mathbf{6}$ show changes in the elemental composition of filaments of $1000{ }^{\circ} \mathrm{C}$ - and $1200{ }^{\circ} \mathrm{C}$ nanofibers as a function of increasing etch time (i.e., distance from the surface). An etch time of $2500 \mathrm{sec}$ corresponded to a depth of $450 \mathrm{~nm}$ for $\mathrm{SiO}_{2}$ film. The $1000^{\circ} \mathrm{C}$-filament contained a large amount of oxygen and just a slight amount of carbon as one would expect based on the rough surface seen in the TEM photograph (Fig.3) . The elemental composition remained unchanged in the filament interior. Fig.6 suggests that filaments of $1200{ }^{\circ} \mathrm{C}$-nanofibers were more oxidation resistant than the $1000{ }^{\circ} \mathrm{C}$-filaments. The atom $\%$ oxygen decreased gradually from the filament surface to the interior and reached ca. 30 atom \% at $2500 \mathrm{sec}$. The carbon and silicon contents showed opposite behaviors, and the filament interior was found to contain a roughly constant $\mathrm{C}: \mathrm{Si}: \mathrm{O}$ atomic ratio of $1: 1: 1$.

Fig. 7 shows XRD profiles of the nanofibers. Both nanofiber types showed very broad bands. The $1000{ }^{\circ} \mathrm{C}$-nanofibers were expected to consist primarily of amorphous silicon oxide, from Fig.5. It was not easy to deduce the structure of the $1200{ }^{\circ} \mathrm{C}$-nanofibers, but the elemental composition shown in Fig.6 corresponded to an

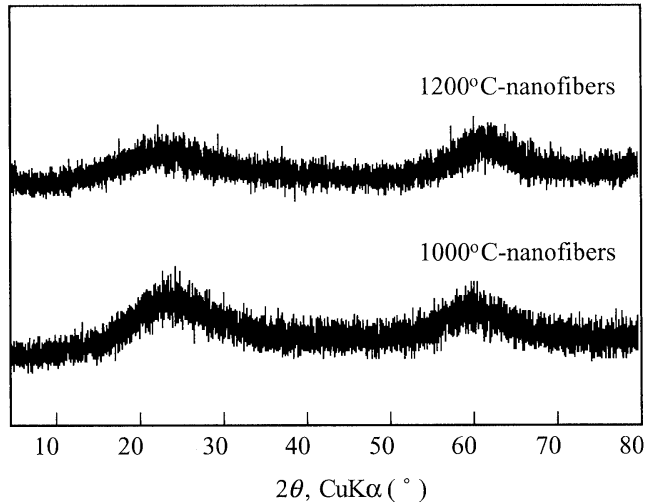

Fig.7 XRD profiles of nanofibers obtained from $1000{ }^{\circ} \mathrm{C}$-blend fibers and $1200{ }^{\circ} \mathrm{C}$-blend fibers.

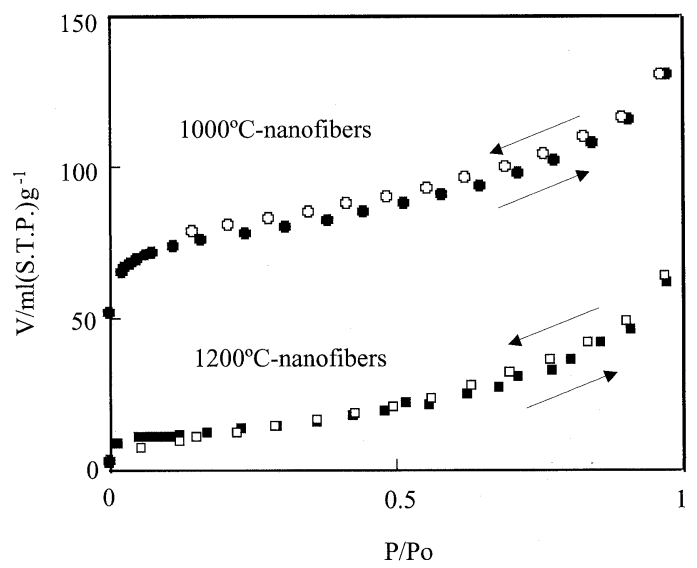

Fig.8 Adsorption/desorption isotherms of nanofibers obtained from $1000^{\circ} \mathrm{C}$-blend fibers and $1200^{\circ} \mathrm{C}$-blend fibers.

amorphous silicon oxycarbide.

As stated above, the nanofibers were oxidized severely by nitric acid. It was quite reasonable to assume that pores were generated by this oxidation process. Fig.8 shows the adsorption/desorption isotherms for both types of nanofiber. Several important points were deduced from the isotherms. Micropores were formed in the $1000^{\circ} \mathrm{C}$ nanofibers more abundantly than in the $1200^{\circ} \mathrm{C}$-nanofibers. Both kinds of nanofibers showed an increase in the adsorbed amount of nitrogen at high $P / P_{0}$, suggesting the presence of macropores. Minor hysteresis was observed between adsorption and desorption isotherms for these nanofibers. It was also surmised that a small amount of mesopores was formed. The specific surface areas (SSA), which are substantially dependent on micropore volume, were $288 \mathrm{~m}^{2} / \mathrm{g}$ and $44 \mathrm{~m}^{2} / \mathrm{g}$ for the $1000{ }^{\circ} \mathrm{C}$ - and $1200{ }^{\circ} \mathrm{C}$-nanofibers, respectively.

The chemical compositions of the two different monofilaments were shown in Figs.5 and 6. Here the following point should be noted. As may be easily supposed, nanofibers in the vicinity of the blend fiber surface were likely released before those in the interior. The former nanofibers would therefore have been oxidized for longer than the latter. Thus, the samples examined doubtless included nanofibers oxidized to varying degrees. It is difficult to gauge from 
Figs.5 and 6 how severely the monofilaments were oxidized. Nevertheless, the significance of the temperature at which the blend fibers were heated was clear, as discussed below. The nanofibers will be evaluated from two points of view, namely with respect to defects and elemental composition. Defects will be discussed initially.

There were two kinds of defects in these nanofibers. One was the surface roughness of the nanofibers, easily recognized in the FE-SEM and the TEM photographs. It was clear from the photographs that nanofibers obtained from the blend fiber heated at $1200^{\circ} \mathrm{C}$ had fewer defects and a smoother surface. Another defect was nitric acid-induced pores, which could be evaluated based on the SSA. The nanofibers prepared from blend fibers heated at $1200{ }^{\circ} \mathrm{C}$ also had the smaller SSA. However, it is known that the high mechanical strength of commercially available PCS-derived Nicalon fiber is drastically reduced upon crystallization induced by heating to temperatures possibly higher than around $1350{ }^{\circ} \mathrm{C}{ }^{12}$ ). This behavior would also be expected of the nanofibers in this study. It could be concluded, therefore, that in order to prepare high quality nanofibers by the present method, the blend fiber needed to be heated at the highest temperature possible without inducing crystallization, because PCS is transformed more completely to an inorganic material at higher temperature.

The next factor is the elemental composition of the nanofibers. The compounds formed in PCS upon heating have been discussed in detail on the basis of XPS data ${ }^{13)}$. As stated above, however, the nanofibers prepared in the present work were individually subjected to varying degrees of oxidation, and it was impossible to know how severely the monofilaments shown in Figs.5 and $\mathbf{6}$ were oxidized. Consequently, only differences in elemental composition between the $1000{ }^{\circ} \mathrm{C}$ - and the $1200{ }^{\circ} \mathrm{C}$-nanofibers will be briefly discussed.

The $1000{ }^{\circ} \mathrm{C}$-monofilament shown in Fig.5 was severely oxidized, although the higher carbon content on the nanofiber surface compared to the interior was curious, and the carbon content of just several \% remained unchanged within the filament interior. The elemental composition in Fig.5 suggested the existence of an amorphous compound with a composition relatively close to that of silicon dioxide. It is known that the oxygen in Nicalon fiber impairs mechanical properties at high temperature, because the oxygen is removed as $\mathrm{CO}$ gas, resulting in defects in the fiber ${ }^{14}$ ).

In contrast to the above, the carbon content in the $1200{ }^{\circ} \mathrm{C}$ monofilament increased gradually from the surface to the interior. The $\mathrm{C}: \mathrm{Si}:$ O ratio was $1: 1: 1$, corresponding to silicon oxycarbide. The composition was unchanged above etch times of ca. $800 \mathrm{sec}$ (corresponding to $144 \mathrm{~nm}$ for $\mathrm{SiO}_{2}$ ). The oxygen content in the $1200{ }^{\circ} \mathrm{C}$-monofilament was far higher than the 13 atom $\%$ for Nicalon heated at $1200^{\circ} \mathrm{C}{ }^{15)}$. Thus, decreasing the oxygen content in these fibers is a major problem yet to be solved. Other open questions are why the elemental composition within each nanofiber is constant and whether the carbon within the nanofibers can survive further oxidation. The results portrayed in Figs.5 and $\mathbf{6}$ clearly indicated that the blend fiber had to be heated to the higher temperature to prepare nanofibers with high carbon content, by more complete transformation of PCS into oxidation-resistant inorganic material.

\section{Conclusions}

Phenolic resin containing fine polycarbosilane particles was spun, stabilized and heat-treated at $1000{ }^{\circ} \mathrm{C}$ or $1200{ }^{\circ} \mathrm{C}$ in an inert atmosphere, followed by oxidation using nitric acid to remove the matrix carbon. The nanofibers thus formed were recovered and their structures were examined, focusing in particular on the effects of temperature during the heat-treatment step. The $1200{ }^{\circ} \mathrm{C}$-nanofibers with diameter less than $1 \mu \mathrm{m}$ showed higher oxidation resistance, and had a smoother fiber surface than $\operatorname{did}$ the $1000{ }^{\circ} \mathrm{C}$-nanofibers. The high oxidation resistance of the $1200{ }^{\circ} \mathrm{C}$-nanofibers gave rise to a smaller specific surface area of $44 \mathrm{~m}^{2} / \mathrm{g}$ against $288 \mathrm{~m}^{2} / \mathrm{g}$ for the $1000{ }^{\circ} \mathrm{C}$ nanofibers. Quantitative elemental analysis using XPS showed that the $1200{ }^{\circ} \mathrm{C}$-filaments contained about 30 atom \% carbon, whereas the carbon content of $1000{ }^{\circ} \mathrm{C}$-filaments was just a few $\%$. Hightemperature heating was required to prepare highly oxidation resistant nanofibers with a large amount of carbon.

\section{References}

1) T. Burchell, Carbon Materials for Advanced Technologies (1999) p.86, Pergamon (Elsevier Science Ltd), Oxford, UK.

2) P. Harris, Carbon Nanotubes and Related Structures. New Materials for the Twenty-first Century (1999), Cambridge University Press, Cambridge, UK.

3) E. Hammel, X. Tang, M. Trampert, T. Schmitt, K. Mauthner, A. Eder and P. Pötschke, Carbon 42 (2004) 1153-1158.

4) G. Chollon, M. Czerniak, R. Pailler, X. Bourrat, R. Naslain, J. Pillot and R. Cannet, J. Mater. Sci. 32 (1997) 893-911.

5) D. Zhou and S. Seraphin, Chem. Phys. Lett. 222 (1994) 233-238.

6) X. Li, L. Liu, Y. Zhang, Sh. Shen, Sh. Ge and L. Ling, Carbon 39 (2001) 159-165.

7) K. Tenmoku, Master's Thesis, Gunma University (2003).

8) Z. Correa, H. Murata, T. Tomizawa and A. Oya, The 32nd Annual Meeting of the Carbon Society of Japan, Ueda, 2005.12.7-9, 1 B07.

9) A. Oya and K. Tenmoku, Japanese Patent Application No. 200532325, A. Oya and K. Tenmoku, International Patent Application No. PCT/Jp2006-301824.

10) T. Mah, N. Lecht, D. E. Mc Cullum, J. R. Hoenigman, H. M. Kim, A. P. Katz and H. A. Lipsitt, J. Mater. Sci. 19 (1997) 1119-1201.

11) J. Rubio, F. Rubio and J. Otelo, J. Mater. Sci. 26 (1991) 2841-2845.

12) N. Hochet, M. Berger and A. Bunsell, J. Microsc. 185 (1997) 243-258.

13) E. Bouillon, F. Langlais, R. Pailler, R. Naslain, F. Cruege, P. V. Huong, J. C. Sarthou, A. Delpuech, C. Laffon, P. Lagarde, M. Monthioux and A. Oberlin, J. Mater. Sci. 26 (1991) 1333-1345.

14) T. Shimoo, I. Tsukada, M. Narisawa, T. Seguchi and K. Okamura, J. Ceram. Soc. Jpn. 105 (1997) 559-563.

15) E. Bouillon, D. Mocaer, J. F. Villeneuve, R. Pailler, R. Naslain, M. Monthioux, A. Oberlin, C. Guimon and G. Pfister, J. Mater. Sci. 26 (1991) 1517-1530. 